\title{
ANÁLISE DAS CONDIÇÕES DE ACESSIBILIDADE DE ROTA TURÍSTICA A PÉ EM PORTO ALEGRE/RS
}

\section{ANÁLISIS DE LAS CONDICIONES DE ACCESIBILIDAD DE LA RUTA A}

PIE EN PORTO ALEGRE / RS

\section{ANALYSIS OF THE ACCESSIBILITY CONDITIONS OF THE TOURIST ROUTE ON FOOT IN PORTO ALEGRE / RS}

Ilmara Pinheiro LIMÃO Universidade Federal do Rio Grande do Sul (UFRGS), Porto Alegre - RS - Brasil. Doutoranda no Programa de Pós-Graduação em Design. ORCID: https://orcid.org/0000-0002-0072-0978.

E-mail: Ilmara.p.limao@gmail.com

Eduardo CARDOSO

Universidade Federal do Rio Grande do Sul (UFRGS), Porto Alegre - RS - Brasil. Professor Adjunto do Departamento de Design e Expressão Gráfica (DEG/FA/UFRGS) e Professor Colaborador no Programa de Pós-Graduação em Design (PGDESIGN/UFRGS). Doutorado em Design (UFRGS). ORCID: https://orcid.org/0000-0002-1202-1779.

E-mail: eduardo.cardoso@ufrgs.br

Fabio Pinto da SILVA

Universidade Federal do Rio Grande do Sul (UFRGS), Porto Alegre - RS - Brasil. Professor Associado do Departamento de Design e Expressão Gráfica (DEG/FA/UFRGS) e Professor Permanente no Programa de Pós-Graduação em Design (PGDESIGN/UFRGS). Doutorado em Engenharia de Minas, Metalúrgica e de Materiais (UFRGS). ORCID: http://orcid.org/0000-0001-9349-5601. E-mail: fabio.silva@ufrgs.br

Ygor CORRÊA Universidade de Caxias do Sul (UCS), Caxias do Sul - RS - Brasil. Pós-Doutorando no Programa de Pós-Graduação em Educação (PPGEdu-UCS). Orcid: https://orcid.org/0000-0002-3526-9195.

E-mail: correaygoprof@gmail.com 
LIMÃO, I.P.; CARDOSO, E, ; SILVA, F.P.; CORRÊA, Y., Análise das condições de acessibilidade de rota turística a pé em Porto Alegre/RS. R. Científica UBM - Barra Mansa (RJ), ano XXVI, v. 23, n. 11,

1. Sem. 2021 p. 115-128. ISSN 1516-4071

\section{RESUMO}

A acessibilidade é um fator essencial em uma sociedade igualitária, devendo garantir o acesso e a qualidade de vida a todos, incluindo as pessoas com deficiências ou mobilidade reduzida. Nessa perspectiva e com base na realidade observada em pesquisa exploratória sobre o turismo acessível em Porto Alegre, foi realizada a análise das condições de acessibilidade física de uma das rotas turísticas a pé da Diretoria de Turismo de Porto Alegre/RS, denominada 'Cruzando o paralelo $30^{\circ}$ : Cidade Baixa'. Na análise, buscou-se identificar se esses locais são acessíveis ao público com deficiência física ou mobilidade reduzida. Os atrativos avaliados no estudo foram os pontos de visitação da rota turística elaborada pela referida Diretoria da Secretaria Municipal de Desenvolvimento Econômico. Para a consecução do objetivo proposto foram realizadas pesquisas de caráter bibliográfico, documental e experimental. Os resultados mostram que a maioria dos pontos turísticos analisados ainda possuem problemas em relação à acessibilidade e, por vezes, eram totalmente inacessíveis. Diante do exposto, o estudo visa colaborar para que sejam adotadas medidas visando promover a acessibilidade nas rotas e atrativos turísticos de Porto Alegre, uma vez que estão diretamente relacionados à história da cidade, e, por isso, devem estar aptos a receber tanto os turistas como os moradores que enfrentam qualquer dificuldade de mobilidade.

Palavras-Chave: Acessibilidade. Rota turística. Turismo acessível.

\section{RESUMEN}

La accesibilidad es un factor esencial en una sociedad igualitaria, y debe garantizar el acceso y la calidad de vida de todos, incluidas las personas con discapacidad o movilidad reducida. En esta perspectiva y a partir de la realidad observada en la investigación exploratoria sobre turismo accesible en Porto Alegre, se realizó un análisis de las condiciones de accesibilidad física de una de las rutas turísticas a pie por la Dirección de Turismo de Porto Alegre / RS, denominado 'Cruzando el paralelo $30^{\circ}$ : Ciudad Baja '. El análisis buscó identificar si estos lugares son accesibles al público con discapacidad física o movilidad reducida. Los atractivos evaluados en el estudio fueron los puntos de visita de la ruta turística elaborada por la referida Dirección de la Secretaría Municipal de Desarrollo Económico. Para lograr el objetivo propuesto se llevó a cabo una investigación bibliográfica, documental y experimental. Los resultados muestran que la mayoría de los puntos turísticos analizados siguen teniendo problemas de accesibilidad y, en ocasiones, totalmente inaccesibles. En vista de lo anterior, el estudio tiene como objetivo colaborar para que se adopten medidas que promuevan la accesibilidad en las rutas y atractivos turísticos de Porto Alegre, ya que están directamente relacionados con la historia de la ciudad y, por tanto, deben poder recibir tanto turistas como los lugareños, que enfrentan dificultades de movilidad.

Palabras Clave: Accesibilidad. Ruta turística. Turismo asequible.

\section{ABSTRACT}

Accessibility is an essential factor in an egalitarian society, and must guarantee access and quality of life for everyone, including people with disabilities or reduced mobility. In this perspective and based on the reality observed in exploratory research on accessible tourism in Porto Alegre, an analysis of the conditions of physical accessibility of one of the tourist routes 
on foot by the Directorate of Tourism of Porto Alegre / RS was carried out, called 'Crossing the parallel $30^{\circ}$ : Lower City'. The analysis sought to identify whether these places are accessible to the public with physical disabilities or reduced mobility. The attractions evaluated in the study were the visitation points of the tourist route elaborated by the referred Directorate of the Municipal Secretariat of Economic Development. In order to achieve the proposed objective, bibliographical, documentary and experimental research was carried out. The results show that most of the tourist points analyzed still have problems in terms of accessibility and, at times, were totally inaccessible. Given the above, the study aims to collaborate so that measures are adopted to promote accessibility on routes and tourist attractions in Porto Alegre, since they are directly related to the history of the city, and therefore, they must be able to receive both tourists as residents who face any mobility difficulties.

Keywords: Accessibility. Tourist route. Accessible tourism.

\section{INTRODUÇÃO}

O bairro Cidade Baixa, em Porto Alegre - Rio Grande do Sul, fica perto do Parque Farroupilha e do Campus Central da Universidade Federal do Rio Grande do Sul (UFRGS), que são pontos de referência da cidade. É conhecido por ser considerado como sinônimo de descontração e boemia, principalmente, no período da noite. Já referente aos seus pontos turísticos, existe um roteiro a ser percorrido a pé criado pela Diretoria de turismo da Secretaria Municipal de Desenvolvimento Econômico, que percorre os pontos turísticos mais relevantes dessa região, sendo esse roteiro base do presente estudo.

A rota turística, denominada 'Cruzando o paralelo $30^{\circ}$ : Cidade Baixa', é composta por doze pontos de visitação são eles: o Caminho dos Antiquários; a Cinemateca Capitólio; a Ponte de Pedra; o Terminal da linha de Turismo e Centro de Informações Turísticas (CIT) de Porto Alegre; a rua João Alfredo, o Museu Joaquim Felizardo; a Travessa dos Venezianos, a rua Lima e Silva, a rua da República, a Redenção (Parque Farroupilha); o Centro Cultural da UFGRS; e o Museu UFRGS.

O mapeamento da acessibilidade na rota turística da cidade baixa tem por objetivo analisar, de forma geral, os aspectos aderentes às pessoas com deficiência física ou mobilidade reduzida, envolvendo visitas e observações técnicas ao longo do percurso, nas vias e mobiliários urbano, assim como das instalações e dos serviços dos principais pontos turísticos do local, principalmente, prédios públicos.

Por meio desse levantamento, é possível identificar a situação existente com vistas a incentivar a promoção da acessibilidade e da adequação dos espaços (urbanos e arquitetônicos), promover a conscientização da comunidade local e dos turistas, em geral, sobre a inclusão de 
LIMÃO, I.P.; CARDOSO, E, ; SILVA, F.P.; CORRÊA, Y., Análise das condições de acessibilidade de rota turística a pé em Porto Alegre/RS. R. Científica UBM - Barra Mansa (RJ), ano XXVI, v. 23, n. 11,

pessoas com deficiência, assim como também contribuir para a elaboração de políticas públicas, de planos e de projetos de acessibilidade.

O presente estudo permite elaborar um diagnóstico geral das condições de acessibilidade em que se encontra a rota turística, fase inicial para que os gestores possam, no futuro, planejar ações que visem melhorias e adaptações nos espaços de uso turístico visando torná-los acessíveis às pessoas com deficiência ou mobilidade reduzida.

Este trabalho está estruturado em: (1) referencial teórico; (2) metodologia; (3) diagnóstico in loco da rota turística da Cidade Baixa; (4) análise e sugestão de rotas para pessoas com deficiência física ou mobilidade reduzida; e considerações finais.

\section{REFERENCIAL TEÓRICO}

Dada a importância cada vez maior do turismo, tanto a nível econômico como em nível social, e da sua capacidade para gerar riquezas e desenvolver regiões, torna-se imperativo que todas as pessoas tenham acesso à experiência turística. Isso conduz a perspectivas mais abrangentes sobre o turismo, com o aparecimento de conceitos como os de turismo acessível e turismo inclusivo (ARAÚJO, 2009).

Entre as várias definições na área do turismo, é fundamental identificar as características e a composição da expressão "Turismo Acessível”, que começou a ser desenvolvida nos anos oitenta, pela Organização Mundial do Turismo (OMT), que na Declaração de Manila reconheceu o turismo como um direito fundamental e o principal meio para o desenvolvimento humano. De modo que se tem incentivado nos estados membros a regulamentação dos serviços turísticos e destacado os aspetos mais importantes da acessibilidade no turismo, sendo este hoje reconhecido como um direito, tanto a nível nacional como internacional, que contribui para uma sociedade mais inclusiva (FERREIRA, 2013).

No final dos anos oitenta, surge outro termo para fazer referência ao turismo para pessoas com deficiência, o "turismo para todos", definido como o conjunto de atividades orientadas para o turismo e lazer para todas as pessoas, independentemente do seu grau de capacidade ou incapacidade (DOMINGUEZ, 2008).

Para Devile et al. (2012) o conceito de "Turismo Acessível", também designado de “Turismo para Todos", reconhece que qualquer pessoa deve poder usar os equipamentos e serviços turísticos e que é necessário proporcionar uma oferta de serviços e atividades orientadas para gostos e preferências de pessoas que tenham um conjunto de limitações a que podem corresponder necessidades e exigências diferentes de outros segmentos da procura. 
LIMÃO, I.P.; CARDOSO, E, ; SILVA, F.P.; CORRÊA, Y., Análise das condições de acessibilidade de rota turística a pé em Porto Alegre/RS. R. Científica UBM - Barra Mansa (RJ), ano XXVI, v. 23, n. 11,

Pode-se afirmar que o turismo acessível, através de processos de colaboração entre seus diversos participantes, apresenta uma oferta de produtos, serviços e ambientes baseados no conceito do Design Universal - de forma a eliminar ou diminuir todos os tipos de barreiras físicas, humanas ou de informação - permitindo às pessoas com qualquer tipo de necessidade específica, assim como aos seus acompanhantes, a prática da atividade turística de uma forma equitativa, digna e segura, sempre orientada para a máxima independência (CARVALHO, 2015).

O aumento dos estudos sobre o turismo acessível contribui para a globalização do turismo, impondo novas atitudes e um conjunto de ações que permitam a democratização da atividade, tornando-a possível para todos os cidadãos. A OMT declarou, em 1980, o turismo como um "direito fundamental e um veículo chave para o desenvolvimento, alertando, para a realidade social desse fenômeno" (CARVALHO, 2015, p. 79). Considera-se acessibilidade um conjunto de características do ambiente edificado que permitem a sua utilização por todas as pessoas, independentemente das suas aptidões físicas, sensoriais ou intelectuais (SIMÕES, 2011).

A acessibilidade é uma condição para utilização de espaços e equipamentos com segurança e autonomia por pessoas com deficiência física ou mobilidade reduzida que, em sua definição, é a dificuldade de se movimentar, seja ela permanente ou temporária (LEAL et al., 2008).

A ideia de mobilidade deve estar voltada para as pessoas e deve valorizar o espaço urbano como lugar de encontro, circulação, cruzamento de diferença e, no caso de centros históricos, lugar de fruição do patrimônio. Em outras palavras, as áreas consagradas como patrimônio cultural devem se constituir em espaços onde é possível conhecer, usufruir e desfrutar do patrimônio cultural (RIBEIRO, 2014).

Rota de pedestre é a atividade de percorrer certas distâncias a pé em caminhos preestabelecidos e sinalizados, exatamente como o que entendemos por trilhas, com a diferença de ser desenvolvida no meio urbano, para a contemplação de bem construído pelo homem (QUEIROZ et al., 2017).

As rotas turísticas têm a função de promover o conhecimento entre diferentes civilizações, culturas e religiões, mostrando suas interrelações e influências recíprocas, conceito este que denominou de rotas de diálogo (SCHLUTER, 2006, p. 74).

$\mathrm{Na}$ perspectiva da oferta turística, a rota é "a criação de um conjunto de atividades e atrações que incentivam a cooperação entre diferentes áreas e servem de veículo para estimular o desenvolvimento econômico através do turismo" (BRIEDENHANN; WICKENS, 2004). 
LIMÃO, I.P.; CARDOSO, E, ; SILVA, F.P.; CORRÊA, Y., Análise das condições de acessibilidade de rota turística a pé em Porto Alegre/RS. R. Científica UBM - Barra Mansa (RJ), ano XXVI, v. 23, n. 11,

As rotas turísticas podem concretizar-se através de diversos meios de transporte ou a pé, o que permite o contato com o patrimônio natural ou cultural de uma área e fornece uma experiência educacional que irá aumentar a satisfação do visitante. Elas podem ser marcadas em sinalização vertical/horizontal ou em mapas, e devem dispor de uma boa literatura de interpretação para orientar o visitante (SILBERGH; FLADMARK; HENRY; YOUNG, 1994, p. 124).

De acordo com Gomez e Quijano (1992), a tipologia das rotas turísticas é determinada a partir da motivação do turista. Estas são classificadas segundo os meios de transporte, a duração, o destino, o segmento de mercado a que se dirige, o número de participantes, a base geográfica, o interesse cultural e o valor artístico. Este estudo trata apenas de uma rota turística, a pé e no contexto urbano, tendo como fator principal as condições de acesso e utilização por pessoas com deficiência física ou mobilidade reduzida.

Segundo Devile (2009), para que um destino turístico tenha potencial para se tornar acessível, é fundamental que se aposte na qualidade, fornecendo as condições adequadas de acessibilidade e investindo na formação dos seus profissionais e na diferenciação dos serviços prestados.

\section{METODOLOGIA}

A caracterização da pesquisa se dá sob o ponto de vista da sua natureza, da sua abordagem, dos seus objetivos e do seu procedimento técnico. (PRODANOV; FREITAS, 2013). Neste caso, a pesquisa é de natureza aplicada, com objetivos descritivos e com procedimentos técnicos, especificamente, bibliográfica, documental e experimental.

Dessa forma, o desenvolvimento deste estudo divide-se em três etapas e cada uma delas envolve um desdobramento de ações. Na primeira etapa de embasamento teórico, a pesquisa bibliográfica e documental é aprofundada, tendo como objetivo entender os principais conceitos acerca do tema tratado e obter mais conhecimento de como solucionar o problema definido previamente; assim, nesta etapa, há a leitura de estudos dos principais autores e a análise dos documentos relacionados ao tema central deste estudo.

Ao considerar que existe um universo gigantesco dentro da temática de acessibilidade, a delimitação do estudo envolve tanto a seleção do produto, quanto a identificação do públicoalvo, na segunda etapa, como também a escolha dos critérios de avaliação que são utilizados. Baseado nisso, pretende-se definir os instrumentos, tecnologias e o público-alvo da pesquisa. 
LIMÃO, I.P.; CARDOSO, E, ; SILVA, F.P.; CORRÊA, Y., Análise das condições de acessibilidade de rota turística a pé em Porto Alegre/RS. R. Científica UBM - Barra Mansa (RJ), ano XXVI, v. 23, n. 11,

Na última etapa os dados são tratados para uma melhor compreensão da problemática. No âmbito da concepção da pesquisa, a análise busca identificar as convergências e as divergências dos dados analisados em diferentes situações. É nesta etapa também que os resultados são discutidos e avaliados.

Referente ao instrumento de coleta de dados, utiliza-se uma técnica estruturada, por meio da observação direta, com roteiro previamente definido pelo grupo observador, composto por pessoas com deficiência, profissionais e estudantes da área. O guia turístico é o profissional responsável por direcionar o grupo e descrever, in loco, todos os pontos presentes no roteiro analisado. Já o grupo observador é responsável verificar os fatores de infraestrutura, como sinalização, faixas de travessia, rebaixos de meio fio e rampas. Também são utilizados registros fotográficos e cronômetro, para auxiliar nos registros do estudo.

$\mathrm{Na}$ análise e na compilação dos dados a ferramenta do Google Maps é utilizada para auxiliar o mapeamento da rota, pois o site oferece imagens de satélite, fotografia aérea, mapas de ruas, vistas panorâmicas interativas de $360^{\circ}$ das ruas, condições de tráfego em tempo real e planejamento de rotas para viagens a pé, de carro, bicicleta e transporte público, de forma online e de livre acesso.

\section{DISCUSSÃO}

\subsection{DIAGNÓSTICO DE ACESSIBILIDADE DA ROTA TURÍSTICA}

A partir dessa etapa, descrevem-se os aspectos identificados in loco pela equipe de pesquisadores no processo de deslocamento entre os pontos da rota turística, denominada 'Cruzando o paralelo $30^{\circ}$ : Cidade Baixa'. Esse percurso foi realizado por pedestres com diferentes níveis de mobilidade, incluindo uma pessoa em cadeira de rodas.

A Figura 1, mostra os registros fotográficos das principais ruas de acessos aos pontos turísticos da rota, como também sinalização, elevador e obstáculos nas vias.

Figura 1 - Registros fotográficos do percurso da rota, 'Cruzando o paralelo $30^{\circ}$ : Cidade Baixa' 
LIMÃO, I.P.; CARDOSO, E, ; SILVA, F.P.; CORRÊA, Y., Análise das condições de acessibilidade de rota turística a pé em Porto Alegre/RS. R. Científica UBM - Barra Mansa (RJ), ano XXVI, v. 23, n. 11, 1. Sem. 2021 p. 115-128. ISSN 1516-4071

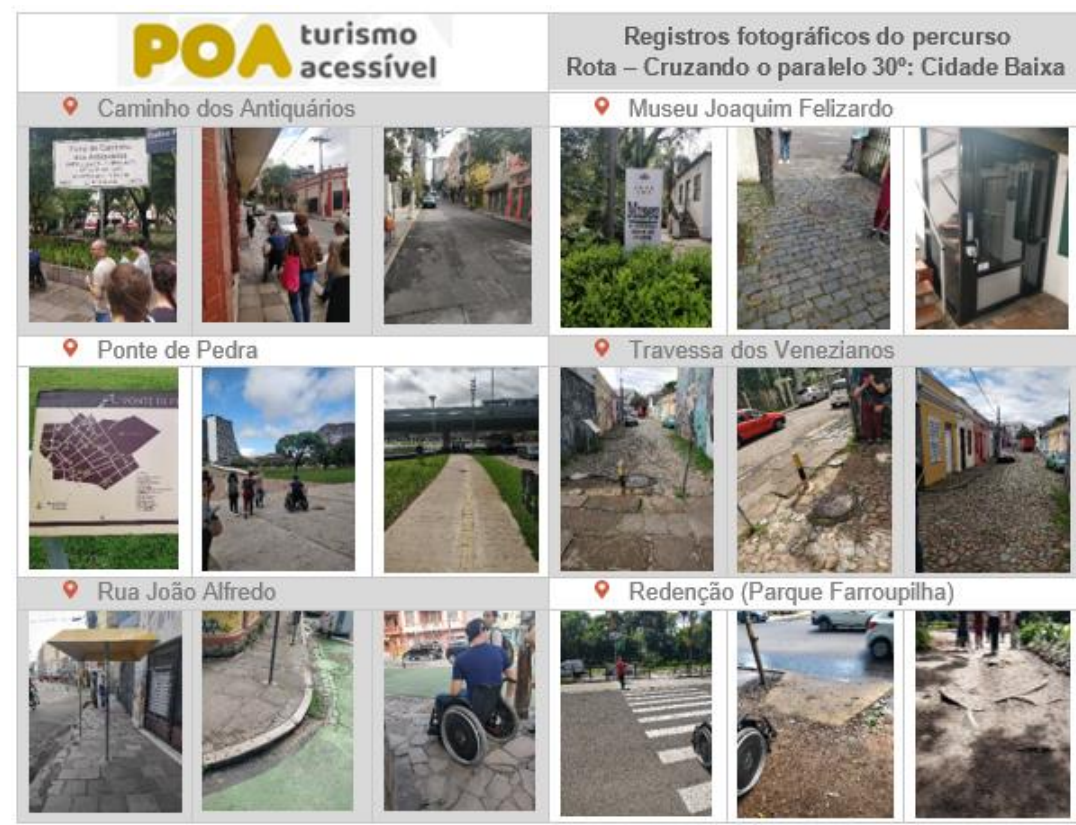

Fonte: Acervo dos autores

Descrição da imagem: painel com 18 fotos divididas em 6 colunas e 4 linhas. Na primeira linha fotos do Caminho dos Antiquários e do Museu Joaquim Felizardo; na segunda, fotos da Ponte de Pedra e da Travessa dos Venezianos; na terceira, fotos da Rua João Alfredo e do Parque Farroupilha.

O levantamento tem por finalidade enfatizar os aspectos que apontem, de forma global e objetiva, a situação da acessibilidade existente no trajeto turístico delimitado, permitindo identificar fatores que impossibilitam o acesso aos pontos turísticos e com isso, gerar informações relevantes referentes aos obstáculos e às dificuldades existentes no meio do percurso. Foi identificada na maior parte do percurso, a ausência de sinalização, de calçamento inadequado, de rampas inacessíveis, dentre outros, como ilustra a Figura 2.

Figura 2 - Registro das dificuldades de acesso, rota 'Cruzando o paralelo $30^{\circ}$ : Cidade Baixa' 
LIMÃO, I.P.; CARDOSO, E, ; SILVA, F.P.; CORRÊA, Y., Análise das condições de acessibilidade de rota turística a pé em Porto Alegre/RS. R. Científica UBM - Barra Mansa (RJ), ano XXVI, v. 23, n. 11,

1. Sem. 2021 p. 115-128. ISSN 1516-4071

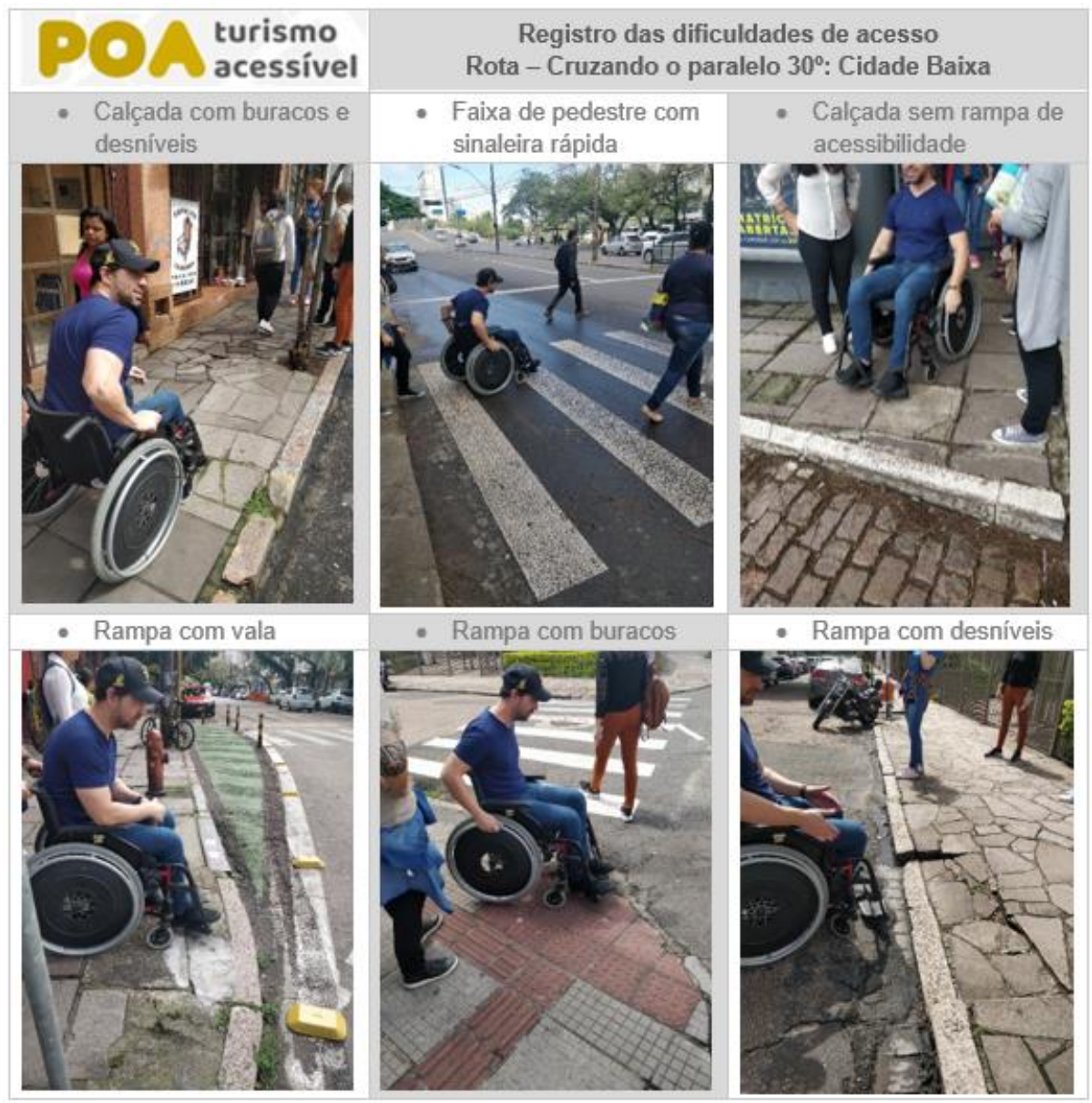

Fonte: Acervo dos autores

Descrição da imagem: painel com 6 fotos divididas em 2 linhas e 3 colunas. Nas fotos um homem em uma cadeira de rodas, em diferentes situações do percurso. Na primeira linha, respectivamente, calçada com buracos e desníveis; faixa de pedestre com sinaleira rápida; calçada sem rampa de acessibilidade. Na segunda linha, rampa com vala; rampa com buracos; rampa com desnível.

De maneira geral, os fatores levantados no diagnóstico preliminar da rota turística, apresentam pontos preocupantes de acesso que requerem um esforço físico maior da pessoa com cadeira de rodas e, em alguns outros pontos, não é possível o acesso sem o auxílio de terceiros. Além dos desníveis no calçamento, também é difícil a travessia na faixa de pedestre por apresentar canteiro central sem rebaixo e sinaleira com tempo insuficiente para a travessia por pessoa com deficiência física ou mobilidade reduzida.

Por fim, por meio do diagnóstico realizado referente à acessibilidade da rota turística da cidade baixa, constatou-se muita dificuldade para concluí-la, especificamente, por pessoa com deficiência física ou mobilidade reduzida.

Diante do exposto, fica evidente que pessoas com deficiência física ou mobilidade reduzida irão encontrar muitos desafios para aproveitar e desfrutar do passeio, tendo em vista as dificuldades já citadas. Sendo assim, é de grande importância a análise detalhada de 
LIMÃO, I.P.; CARDOSO, E, ; SILVA, F.P.; CORRÊA, Y., Análise das condições de acessibilidade de rota turística a pé em Porto Alegre/RS. R. Científica UBM - Barra Mansa (RJ), ano XXVI, v. 23, n. 11,

acessibilidade da rota turística da Cidade Baixa, apontando as dificuldades e buscando, a partir desses dados, a melhoria das condições de acessibilidade da rota turística.

\subsection{ANÁLISE DE ACESSIBILIDADE DA ROTA TURÍSTICA E PROPOSIÇÃO DE FERRAMENTAS}

Baseando-se no diagnóstico apresentado e levando-se em consideração os 12 pontos turísticos da rota, se estabeleceu uma relação entre eles e três critérios para a identificação de rotas alternativas mais agradáveis para o deslocamento e fruição por pessoas com deficiência física ou mobilidade reduzida. Foram estabelecidos enquanto critérios para relação: o esforço físico; a distância; e, o tempo do percurso da rota turística. A seguir são apresentadas algumas ferramentas criadas para informar o visitante sobre as possibilidades de rotas de acordo com os critérios elencados, sempre balizados por parâmetros como o conforto e a autonomia do usuário durante a visitação. A Figura 3, relaciona os doze pontos de visitação do circuito e sugere três possibilidade de rotas: completa; moderada; e, fácil.

Figura 3 - Quadro das rotas alternativas da Rota 'Cruzando o paralelo 30: Cidade Baixa'

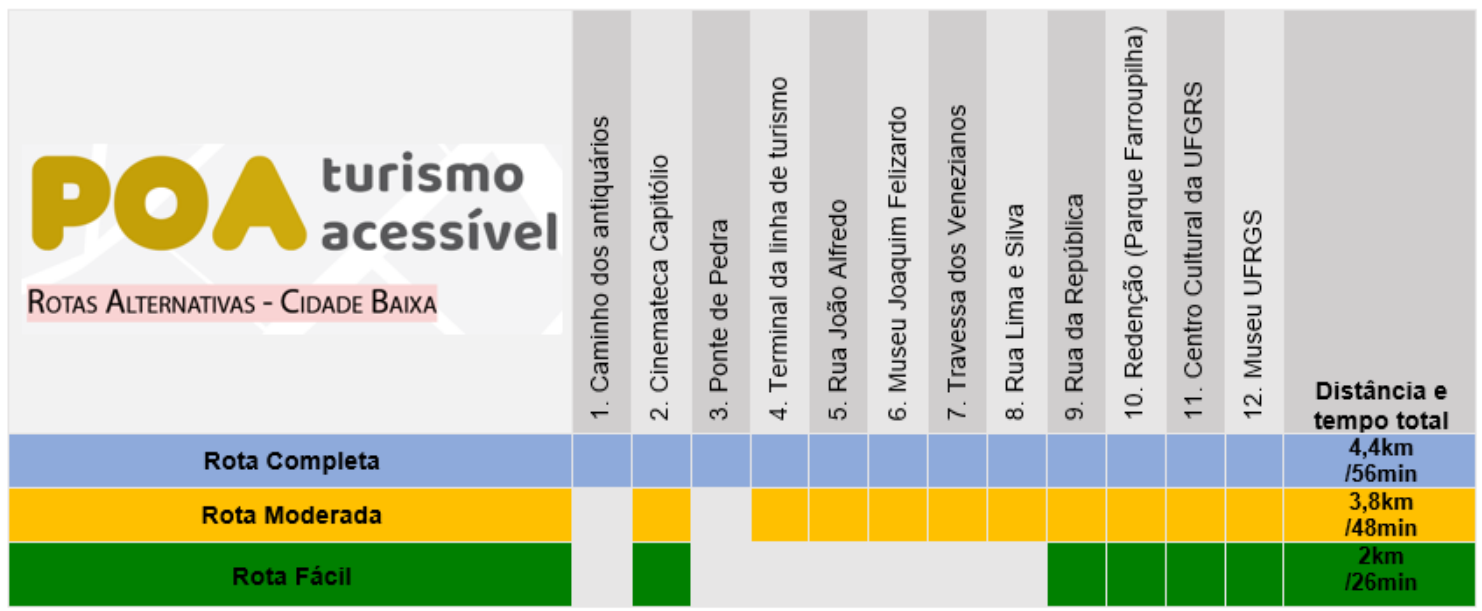

Fonte: Acervo dos autores

Descrição da imagem: Quadro em cores da relação das alternativas de rotas turísticas, cada uma em uma linha colorida, e os 12 pontos turísticos da rota. Em uma linha azul, Rota Completa; em uma linha Rota Moderada; e em uma linha verde, Rota Fácil. Os 12 pontos turísticos são, respectivamente, 1. Caminho dos Antiquários, 2. Cinemateca Capitólio, 3. Pode de Pedra, 4. Terminal da linha Turismo, 5. Rua João Alfredo, 6. Museu Joaquim Felizardo, 7. Travessa dos Venezianos, 8. Rua Lima e Silva, 9. Rua da República, 10. Redenção (Parque Farroupilha), 11. Centro Cultural da UFRGS, 12. Museu da UFRGS. 
LIMÃO, I.P.; CARDOSO, E, ; SILVA, F.P.; CORRÊA, Y., Análise das condições de acessibilidade de rota turística a pé em Porto Alegre/RS. R. Científica UBM - Barra Mansa (RJ), ano XXVI, v. 23, n. 11,

A rota completa é o percurso que passa em todos os pontos turísticos da rota proposta pela Diretoria Municipal de Turismo, mesmo apresentado alguns pontos de difícil acesso e utilização. Na rota moderada, são retirados dois pontos turísticos, o Caminho dos Antiquários e a Ponte de Pedra, por apresentarem rua inclinada e calçamento irregular, respectivamente. Já na rota fácil é traçado um trajeto mais curto que retira além dos dois pontos anteriores, os pontos do Terminal da Linha de Turismo e CIT de Porto Alegre, a rua João Alfredo, o museu Joaquim Felizardo, a travessa dos Venezianos e a rua Lima e Silva, por apresentarem alguns pontos de difícil acesso.

No mapa da rota turística da Cidade Baixa, ilustrada na Figura 4, são representados três tipos de vias ou rotas com suas respectivas legendas: um seguimento contínuo para a via/rota regular; um seguimento tracejado para rua acidentada; um seguimento com setas para rua inclinada e um seguimento com desenhos irregulares para pavimento irregular, como trechos em pedra portuguesa ou de difícil circulação de pessoas em cadeiras de rodas. No mapa, ao longo do percurso, as rotas são identificadas por cor conforme o Figura 4. E os pontos turísticos são representados no mapa por meio de pictogramas e marcadores com numeração.

Figura 4 - Mapa da Rota 'Cruzando o paralelo 30: Cidade Baixa'

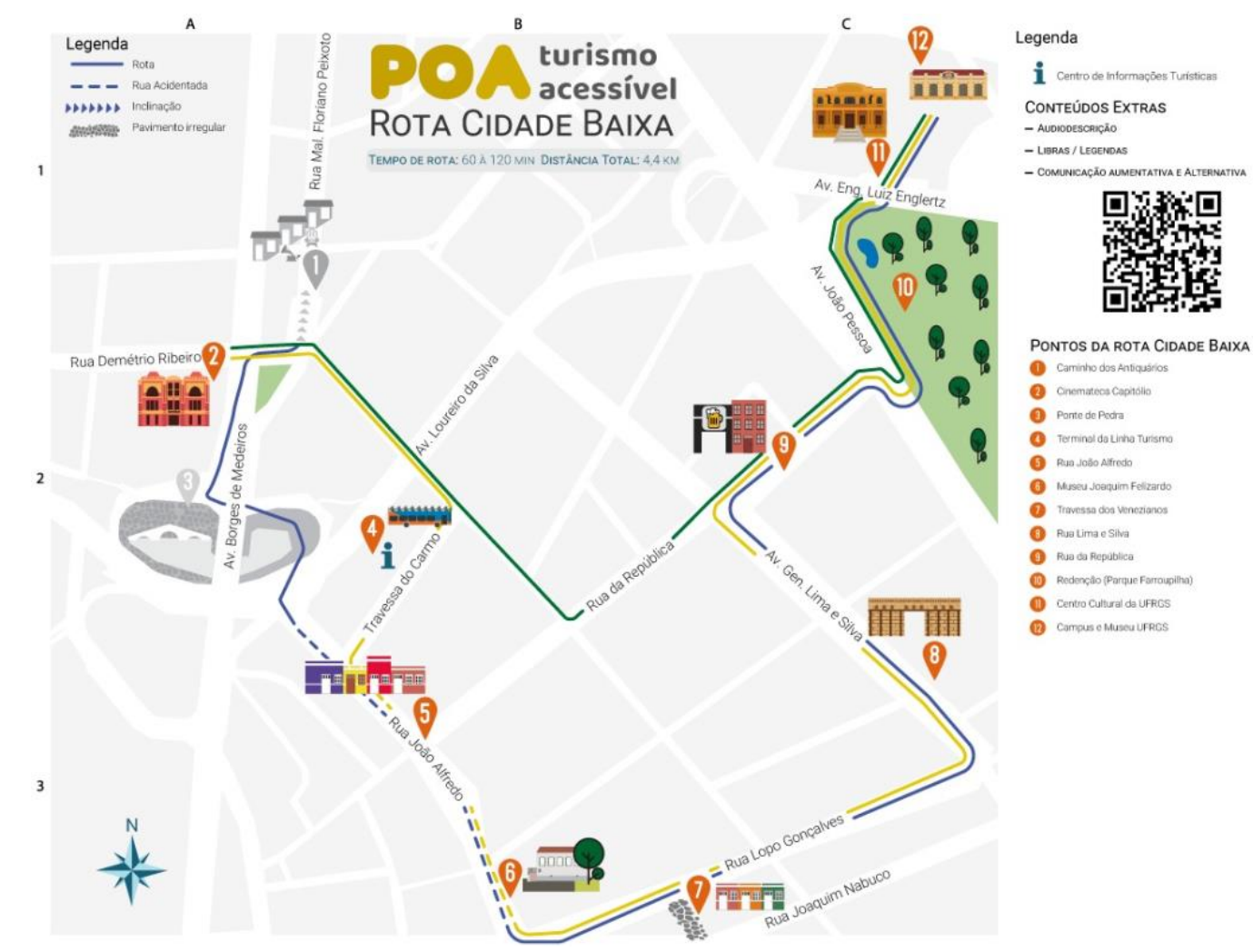

Fonte: Acervo dos autores

Descrição da imagem: mapa da rota Cidade Baixa. Figura quadrada de fundo cinza claro com o desenho das 3 alternativas de rotas turísticas e 12 pontos turísticos marcados com desenhos coloridos. À direita a legenda do mapa e mais informações, como um QR code. 
LIMÃO, I.P.; CARDOSO, E, ; SILVA, F.P.; CORRÊA, Y., Análise das condições de acessibilidade de rota turística a pé em Porto Alegre/RS. R. Científica UBM - Barra Mansa (RJ), ano XXVI, v. 23, n. 11,

Para facilitar o acesso à informação sobre a rota turística da Cidade Baixa, a Figura 5 mostra a relação entre a distância e o tempo para deslocamento entre os pontos de visitação, assim como o somatório de tempo e de distância para os deslocamentos.

Figura 5 - Quadro da relação distância e tempo, rota 'Cruzando o paralelo $30^{\circ}$ : Cidade Baixa'

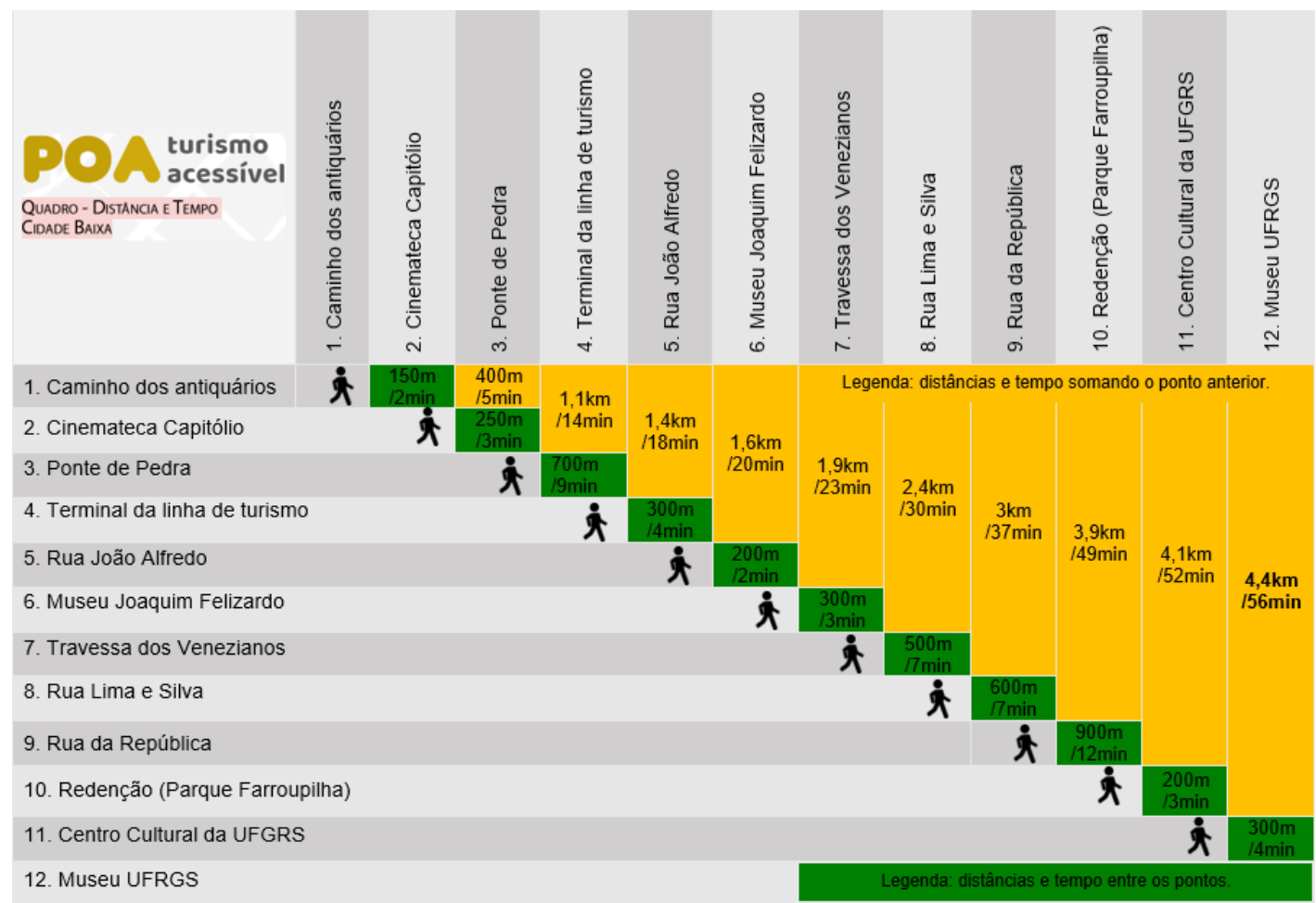

Fonte: Acervo dos autores

Descrição da imagem: Quadro cinza com 12 linhas e 12 colunas relacionando os 12 pontos turísticos da rota entre si para discriminar o tempo e distância entre eles. Na diagonal, em quadrados verdes, a distância e tempo entre cada ponto, e, em amarelo o somatório dos pontos percorridos

As informações em verde são acerca da distância e do tempo entre dois pontos turísticos. As informações em amarelo são de somatório em relação ao ponto anterior, ou seja, é considerando a ligação ao longo de todo o percurso. É importante ressaltar que não é considerado o tempo de parada para visitação em cada local e sim, o tempo de deslocamento do pedestre entre os pontos de visitação.

Tanto os quadros quanto o mapa são ferramentas criadas para facilitar o acesso do usuário à rota denominada 'Cruzando o paralelo $30^{\circ}$ : Cidade Baixa' e, especialmente, aprimorar 
LIMÃO, I.P.; CARDOSO, E, ; SILVA, F.P.; CORRÊA, Y., Análise das condições de acessibilidade de rota turística a pé em Porto Alegre/RS. R. Científica UBM - Barra Mansa (RJ), ano XXVI, v. 23, n. 11,

o turismo acessível da localidade em estudo. Os resultados obtidos neste projeto serão disponibilizados no site $^{1}$ : para consulta e download do material produzido.

É importante enfatizar que o estudo não foi testado com um número considerável de pessoas com deficiências ou mobilidade reduzida, mas que se pretende nas fases seguintes realizar novos testes na rota com usuários com deficiência física em cadeira de rodas e com pessoas com mobilidade reduzida, para avaliar o material proposto e realizar eventuais refinamentos. Com a conclusão desses trabalhos futuros, o público poderá ter acesso ao material informativo, por exemplo, um panfleto ou pôster, no momento da visitação da rota turística.

\section{CONSIDERAÇÕES FINAIS}

Com a finalidade de realizar um levantamento dos aspectos de acessibilidade, especificamente na rota turística a pé da Cidade Baixa em Porto Alegre/RS, o estudo propôs identificar in loco as possíveis dificuldades de locomoção e a utilização de pedestres no momento de deslocamento entre os pontos da rota, incluindo pessoas com deficiência física ou mobilidade reduzida.

O estudo mostrou uma realidade em que todos os pontos turísticos analisados apresentaram problemas em relação à acessibilidade para pessoas com deficiência física ou mobilidade reduzida. Nos pontos de parada da rota é possível encontrar rampas de acesso para cadeirantes, porém estão em mau estado de conservação e não há piso tátil na maioria do percurso.

Portanto, é importante enfatizar a situação da acessibilidade existente no trajeto turístico analisado, pois permite à população o acesso à informação, e, aos gestores, a possibilidade de tomada de decisão devidamente embasada e a formulação de políticas públicas voltadas para a área, destacando as ações que devem ser realizadas, assim como os ajustes em conformidade com a legislação.

\section{REFERÊNCIAS}

ARAÚJO, L.C.D. Perspectivas de inclusão e acessibilidade para o turismo de aventuras. 2009. Monografia (Trabalho de Conclusão de Curso) - Universidade Federal de Minas Gerais, Belo Horizonte, 2009.

\footnotetext{
${ }^{1}$ Disponível em: http://www.ufrgs.br/poaturismoacessível. Acesso em: 10 set. 2020.
} 
LIMÃO, I.P.; CARDOSO, E, ; SILVA, F.P.; CORRÊA, Y., Análise das condições de acessibilidade de rota turística a pé em Porto Alegre/RS. R. Científica UBM - Barra Mansa (RJ), ano XXVI, v. 23, n. 11,

BRIEDENHANN, J.; WICKENS, E. Tourism routes as a tool for the economic development of rural areas. Buckinghamshire Chilterns University College: Tourism Management, 2004. p. 71-79.

CARVALHO, I. O turismo acessível: estratégias de adaptação de uma cidade. O caso de Lisboa. 2015. Tese (Doutorado) - Universidade de Lisboa, Lisboa, 2015.

DEVILE, E. L. O desenvolvimento do Turismo Acessível: dos argumentos sociais aos argumentos de mercado. In: Turismo Acessível. Revista Turismo e Desenvolvimento, n. 11, p. 39-46, 2009.

DEVILE, E. L.; GARCIA, A.; CARVALHO, F.; NEVES, J. Turismo Acessível em Portugal: Estudo de casos de boas práticas. Revista Turismo e Desenvolvimento, v. 3, n. 17/18, p. 626-638, 2012.

DOMINGUEZ, T. Marketing Turístico para personas com discapacidad, el producto turístico accesible. 2008. Tese. (Doutorado) - Universidad de Vigo, Vigo, 2008.

FERREIRA, A. Turismo acessível: Oportunidades, desenvolvimento e desafios. 2013. Tese (Mestrado) - Escola Superior de Hoteleria e Turismo do Estoril, Estoril, Portugal, 2013.

GOMEZ, J.; QUIJANO, G. Rutas e itinerarios turísticos en España. Vallehermoso: Editora Sintesis, 1992.

LEAL, V. L. D. et al. Turismo acessível: uma análise sobre a acessibilidade dos atrativos turísticos localizados no centro histórico de Porto Alegre - RS. In: VANZELLA, E.; BRAMBILLA, A.; SILVA, M. F. T\&H: Turismo e Hotelaria no contexto da acessibilidade. João Pessoa: Editora CCTA, 2018. p. 73-106.

PRODANOV, C. C.; FREITAS, E. C. Metodologia do trabalho científico. 2. ed. Novo Hamburgo, RS: Feevale, 2013.

QUEIROZ, A. S et al. Rota de pedestres em João Pessoa/PB: Dificuldades e oportunidades para o city tour. Applied Tourism, v. 2, n. 3, p. 156-178, 2017.

RIBEIRO, S. B. Mobilidade e acessibilidade urbana em centros históricos. Brasília: Iphan, 2014.

SCHULTER, R. Gastronomia e turismo. São Paulo: Aleph, 2006.

SIMÕES, J. Acessibilidade - Um direito de cidadania. In: Autonomia e acessibilidade: Fazer uma cidade para todos, Encontro Internacional. Lisboa: Centro de Reuniões da Fil/ Parque das Nações/ Câmara Municipal de Lisboa/Grafismo, Lda, 2011. 